\title{
A Constructive Solution that Can Function As a Force Machine or As a Work Machine
}

\section{Mariana Mirela STOICAN (PRISECARU) \& Nicolae BĂRAN}

${ }^{I}$ PhD Student, ${ }^{2}$ Prof. Dr. Eng., Faculty of Mechanical Engineering and Mechatronics, Department of Thermodynamics, Engines, Thermal and Refrigerating Equipment's, ${ }^{1}$ University Politehnica of Bucharest.Email: mirela.prisecaru@yahoo.com ${ }^{1} \&$ _n_baran_fimm@yahoo.com ${ }^{2}$

\section{ABSTRACT}

The constructive solution of this rotary machine was not physically made for various reasons. A prototype of this machine was made in the laboratory of the Faculty of Mechanical and Mechatronics Engineering, Department of Thermotechnics, Engines, Thermal and Refrigeration Equipment a POLITEHNICA University of Bucharest, and experimental research has shown that the constructive solution is functional. We have a calculation program for making this machine that circulates any kind of fluid. We look forward to any form of collaboration on this topic.

Keywords: Rotating Machine, Profiled Rotor, Rotating Piston.

\section{Introduction}

Rotating machines with profiled rotors are meet in the technique both as force machines and as working machines. [1] [2]. Deepening the theoretical aspects and finding new solutions to solve problems related to the transformation of different forms of energy into other forms of energy is a current need that is partially solved by this paper.

The machines, according to their purpose are divided into two main classes [3] [4] [5]:

1. Force machines (motor cars), which convert a certain form of energy into mechanical energy (internal combustion engines, steam or gas turbines, etc.) and in this case the suction fluid pressure (p1) is higher than the discharge pressure (p2);

2. Working machines, which convert mechanical energy into another form of energy (compressors, fans, pumps), $\mathrm{p}_{1}<\mathrm{p}_{2}$

The force and working machines that are traversed by fluids, according to the variation of the flow parameters, are classified as follows:

a) Hydraulic machines, which drive or are driven by liquids, which neglects the thermal phenomena;

b) Thermal machines, which carry gases or vapors (or are driven by it), which do not neglect the thermal phenomena that occur.

The most widespread are the thermal machines which, according to the operating principle, are classified as follows:

a) Reciprocating piston machines;

b) Rotating machines (with profiled rotors or blades);

c) Jet engines.

A classification of rotating machines with profiled rotors is presented in table 1 . 
Table 1: Classification of rotating machines with profiled rotors

\begin{tabular}{|l|l|}
\hline \multicolumn{1}{|c|}{ Classification by purpose } & Classification in terms of construction \\
\hline \multirow{4}{*}{ Working machines } & Pumps for driving fluids or with suspensions \\
\cline { 2 - 2 } & Fans for transporting gases or vapors \\
\cline { 2 - 2 } & Blowers for gas and vapor compression \\
\hline \multirow{4}{*}{ Force machines } & Hydraulic motor \\
\cline { 2 - 2 } & Pneumatic motor \\
\cline { 2 - 2 } & Steam engine or combustion gases \\
\hline
\end{tabular}

Such a machine must provide:

- transforming the useful moment with minimal losses when it works as a working machine.

- maximum use of the energy of the working agent for shaft actuation when it is working as a force machine.

\section{The Operating Principle and Constructive Solutions of the Rotating Machine}

The fluid aspired into the suction connection (2) figure 1, is transported by a rotation movement by the pistons (6) to the discharge connection (5), the fluid can be polyphase (air + water, water + sand, water + steam, water + ash, etc.) or it may be viscous, or high density. The machine has two profiled rotors that rotate counterclockwise inside some casings. The synchronous rotation of two rotors $(3,7)$ is ensured by means of two gear wheels $(8)$ that form a cylindrical gear with straight teeth, gear wheels located outside the machine.

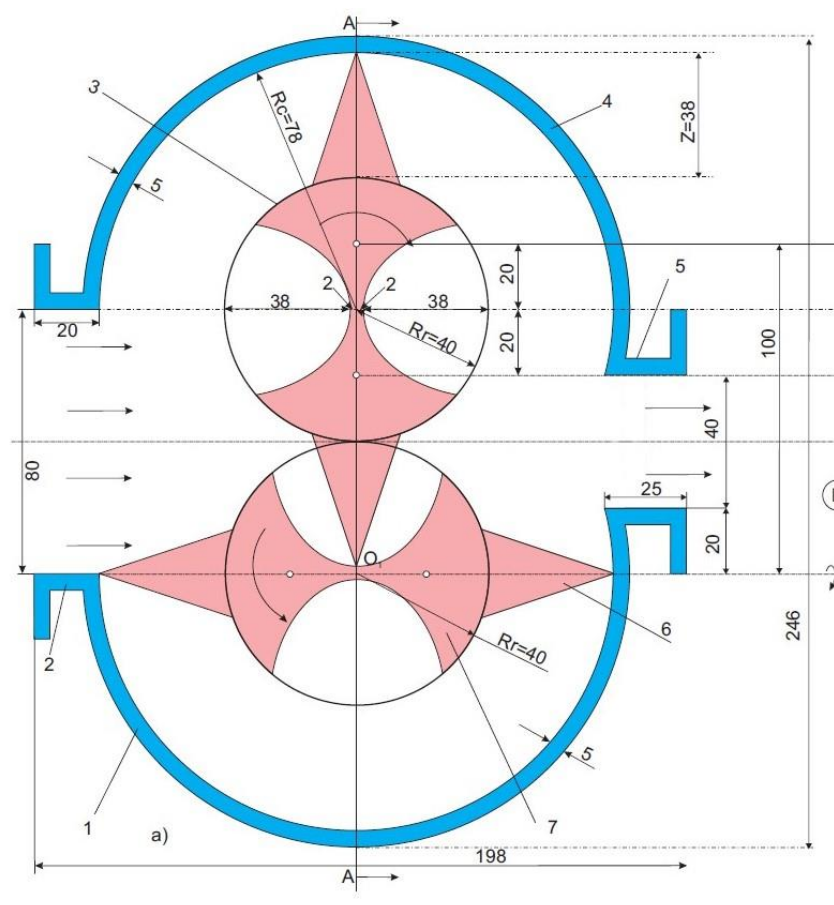

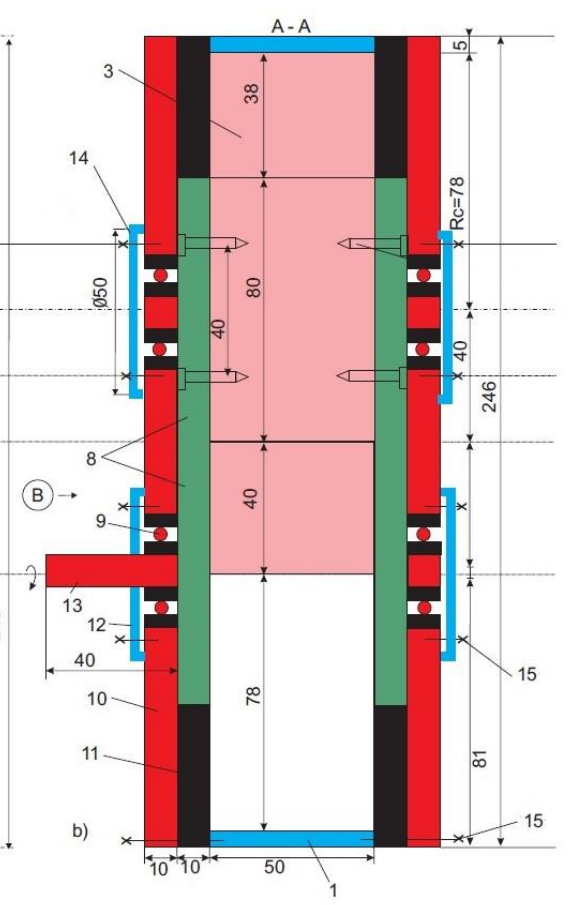

Fig. 1: Cross Section (A) and Longitudinal Section (B) Through the Rotating Machine 
a: 1 - lower case; 2 - fluid suction connection; 3 - upper rotor; 4 - upper case;

5 - fluid discharge connection; 6 - rotating piston; 7 - lower rotor;

b: 8 - gears wheels; 9 - bearings; 10 - side wall (left) of the case; 11 - intermediate wall;

12 - bearing cover; 13 - driving shaft; 14 - sealing caps; 15 - clamping screws.

Figure 1 shows the constructive solution of the rotating machine with profiled rotors, when the rotors are not crossed by shafts. The constructive solution has the following particularities:

a) The shaft for each rotor does not penetrate inside the rotor, thus $\mathrm{z} \rightarrow \mathrm{R}_{\mathrm{r}}$;

b) The shaft drives the lower rotor through a flange fixed with rotor screws; the flange rotates inside the side wall of the machine case (figure 1.b);

The elaboration of this constructive solution aims to validate the previously established conclusion, namely that the value of $\mathrm{z}$ must tend to $\mathrm{R}_{\mathrm{r}}$.

Figure 2 shows a section through the rotating machine designed in the CATIA V5 program, representing a side view for the right side wall.

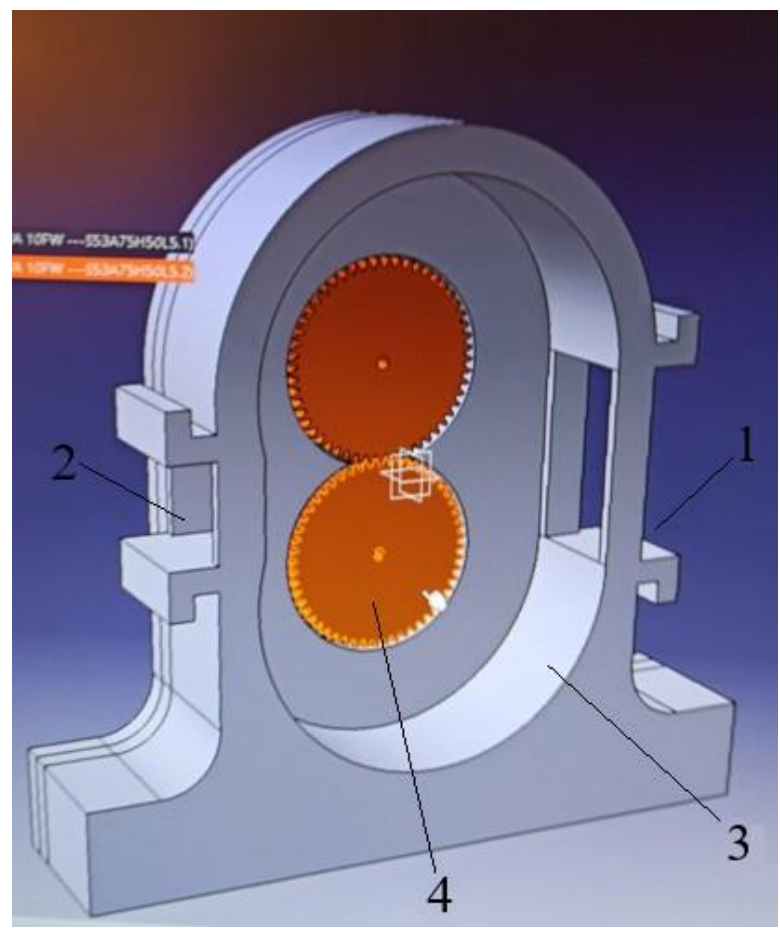

Fig 2: View For Right Side Wall

1 - fluid suction connection; 2 - fluid discharge connection; 3 - rotating machine case;

4 - gears wheels with division diameter $\emptyset=40$; thickness $10 \mathrm{~mm}$.

\section{Establishing the Mathematical Relation between the Rotor Radius and the Height of the Rotating Piston}

In order, to establish this connection mathematically, let us consider the two rotors of the machine, tangent at point K. 
It is considered one piston (5) fixed to the lower rotor (Figure 3).

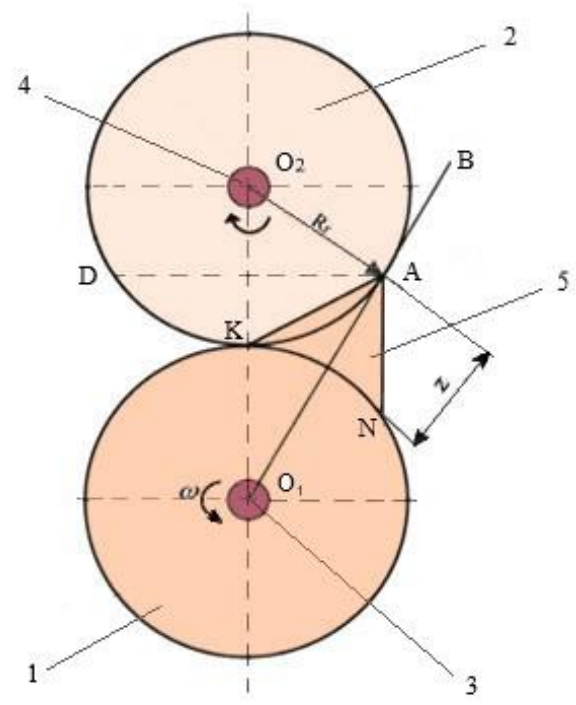

Fig 3: Calculation Notations

1 - lower rotor; 2 - upper rotor; 3 - driving shaft; 4 - driven shaft;5 - rotating piston of triangular shape.

The rotor radius (1) is extended by a length ( $\mathrm{z}$ ) and thus the line $\mathrm{O}_{1} \mathrm{~B}$ reaches the rotor (2) at point A. Theoretically, when point $\mathrm{K}$ reaches point $\mathrm{D}$, point $\mathrm{A}$ reaches $\mathrm{K}$, respectively point $\mathrm{N}$ reaches $\mathrm{K}$, because the length of the circle $\operatorname{arcs} \mathrm{AK}, \mathrm{KD}$ and $\mathrm{KN}$ is the same. When the piston (5) exits the gap created in the rotor (2), points $\mathrm{A}$ and $\mathrm{N}$ reach point $\mathrm{K}$; the sealing between the two rotors being ensured by the direct contact between the lateral surfaces of the rotors.

From the right triangle $\mathrm{O}_{1} \mathrm{O}_{2} \mathrm{~A}$ results [3]:

$$
\begin{gathered}
O_{1} O_{2}^{2}=A O_{2}^{2}+A O_{1}^{2} \\
\left(2 R_{r}\right)^{2}=R_{r}^{2}+\left(R_{r}+z\right)^{2}
\end{gathered}
$$

relation that becomes:

$$
z^{2}+2 R_{r} z-2 R_{r}^{2}=0
$$

It is known that between two roots of the function there is a maximum or minimum point of the function; for this purpose, the relation (8) is derived according to $\mathrm{z}$ and one can obtain:

$$
\begin{gathered}
2 z+2 R_{r}=0 \\
z=-R_{r}
\end{gathered}
$$

From the relation (5) the maximum value of the rotating piston height appears, it should be equal to the rotor radius. Basically, this condition can be partially achieved because: 
- if $\mathrm{z}=\mathrm{R}_{\mathrm{r}}$ then the fluid can flow in the "reverse direction" from the discharge to the suction between the gaps (orifices) between the two rotors; $\mathrm{z}<\mathrm{R}_{\mathrm{r}}$ is chosen.

- the shafts on which the rotors are fixed must disappear.

This is possible by fixing the rotors to the gears wheels, wheels having their shafts (figure 4).

The calculation program has an increased accuracy of 8 decimals, because the rotors are executed on a numerically controlled center (C.N.C) [7].

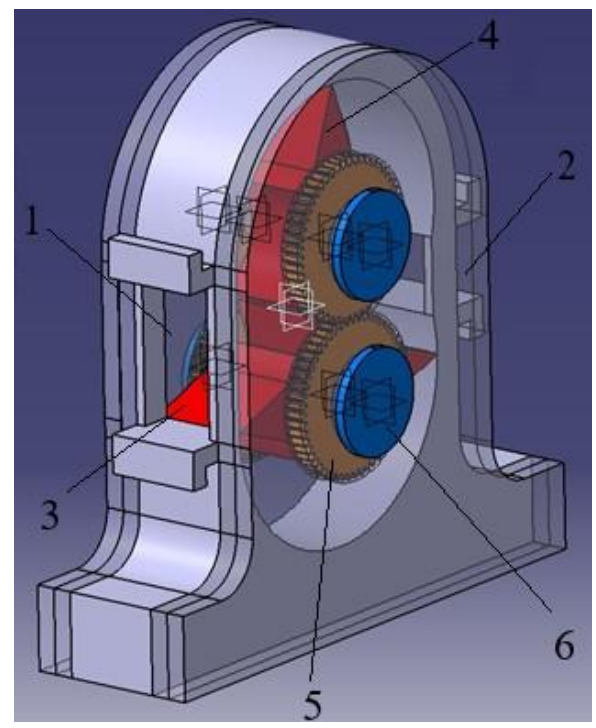

Fig 4: Axonometric View of the Newly Designed Volumetric Pump Model with Profiled Rotors

1- suction chamber; 2 - discharge chamber; 3- lower rotor; 4- upper rotor; 5- gears wheels; 6 - sealing caps.

\section{Establishing the Contour of a Rotor Profile}

The contour of the rotor (figure 3) consists of straight lines, circle arcs and curves for which mathematical calculations relation have been established separately and subsequently a quite complicated computation program has been developed [8].

The contour is specified by the coordinates of points $\mathrm{x}_{\mathrm{i}} ; \mathrm{y}_{\mathrm{i}}$ located as follows:

- On the cavity contour in the rotor, the $A B$ curve;

- On the rotor contour, the arc $B C$;

- On piston side, the line $C D$.

Consider a single piston attached to the upper rotor (figure 5). Based on relations 6 and 7, the value of the angle $\theta$ is calculated.

$$
\begin{gathered}
x_{A}=2\left(R_{C} \cos \theta-R_{r}\right) \cdot \sqrt{1-\cos ^{2}} \theta \\
y_{A}=2 \cos \theta \cdot\left(R_{c} \cos \theta-R_{r}\right)-R_{c}
\end{gathered}
$$



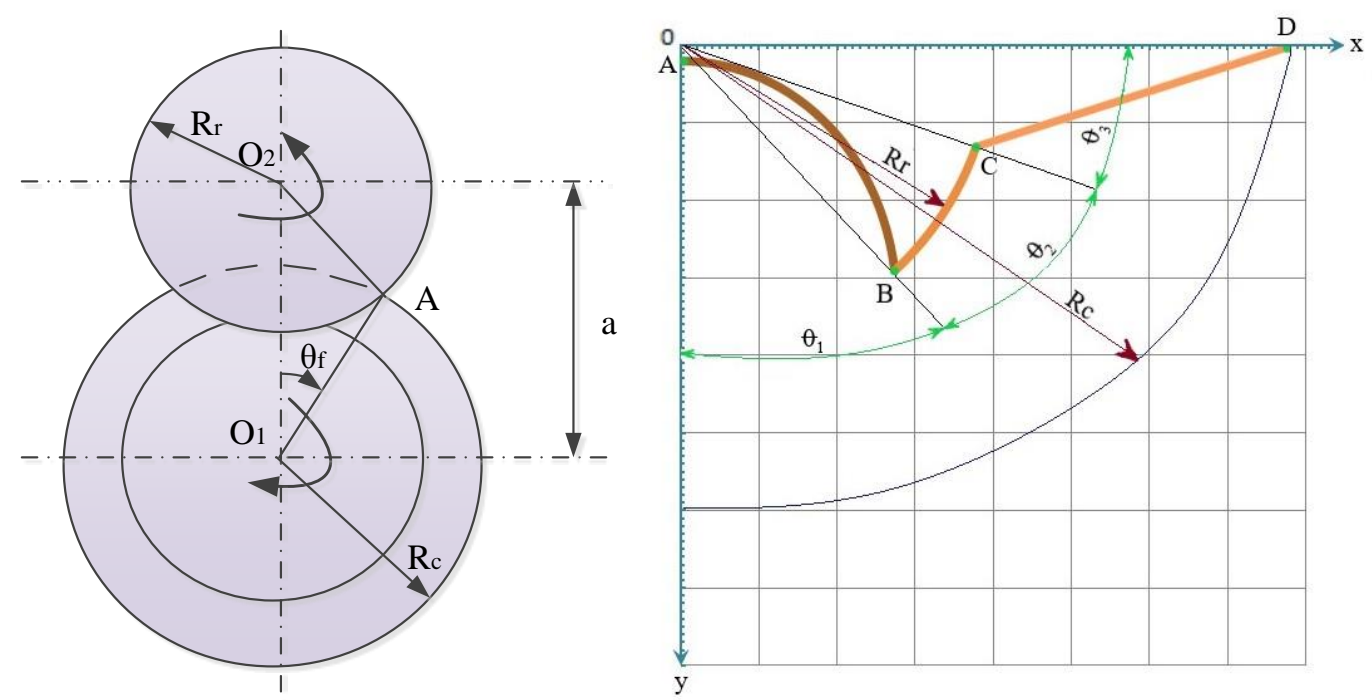

Fig 5: Calculation Notations for Determining the Contour of the Profiled Rotor Profile

From figure 5 one can observe: $O_{1} A=R_{c}=c ; O_{2} A=R_{r}=b ; O_{1} O_{2}=2 R_{r}=a$, wheelbase [m]. The cosine theorem is applied in the triangle $O_{1} O_{2} A$ and it turns aut [9] [10]:

$$
\cos \theta_{f}=\frac{R_{c}{ }^{2}+3 R_{r}{ }^{2}}{4 R_{c} R_{r}}
$$

The following values are chosen: $R_{c}=78[\mathrm{~mm}], R_{r}=40[\mathrm{~mm}]$ and can obtain:

$$
\cos \theta_{f}=\frac{78^{2}+3(40)^{2}}{4 \cdot 78 \cdot 40}=\frac{10884}{12480}=0,872115384
$$

which corresponds to an angle $\theta_{f}=29,2946^{\circ}$.

In order to obtain the coordinates of points $\left(x_{\mathrm{i}}, y_{\mathrm{i}}\right)$, the values are entered in relations (6) and (7): $R_{c}=78 \cdot 10^{-3}$ $[\mathrm{m}] ; R_{r}=40 \cdot 10^{-3}[\mathrm{~m}]$ şi $\theta_{f}=1^{0}, 2^{0} \ldots . .29,2946^{\circ}$; the last point is calculated with the value $\theta_{f}=29,2946^{0}$.

The coordinates of the rotor profile points on the circle portion $\mathrm{BC}$ and $\mathrm{CD}$ are shown in Table 2 and Table 3 , respectively.

Table 2. Coordinates of Points Located on a Radius Circle $R_{r}$

\begin{tabular}{|c|c|c|c|c|c|c|c|}
\hline Nr. & $\theta_{2}$ & $x_{i}[\mathrm{~m}]$ & $\mathrm{y}_{\mathrm{i}}[\mathrm{m}]$ & $\mathrm{Nr}$ & $\theta_{2}$ & $x_{i}[\mathrm{~m}]$ & $\mathrm{y}_{\mathrm{i}}[\mathrm{m}]$ \\
\hline 1 & 43,28 & 0,027422571 & $-0,029120484$ & 16 & 58 & 0,033921924 & $-0,021196771$ \\
\hline 2 & 44 & 0,027786335 & $-0,028773592$ & 17 & 59 & 0,034286692 & $-0,020601523$ \\
\hline
\end{tabular}




\begin{tabular}{|c|c|c|c|c|c|c|c|}
\hline 3 & 45 & 0,028284271 & $-0,028284271$ & 18 & 60 & 0,034641016 & $-0,02$ \\
\hline 4 & 46 & 0,028773592 & $-0,027786335$ & 19 & 61 & 0,034984788 & $-0,019392385$ \\
\hline 5 & 47 & 0,029254148 & $-0,027279934$ & 20 & 62 & 0,035317904 & $-0,018778863$ \\
\hline 6 & 48 & 0,029725793 & $-0,026765224$ & 21 & 63 & 0,035640261 & $-0,01815962$ \\
\hline 7 & 49 & 0,030188383 & $-0,026242361$ & 22 & 64 & 0,035951762 & $-0,017534846$ \\
\hline 8 & 50 & 0,030641778 & $-0,025711504$ & 23 & 65 & 0,036252311 & $-0,01690473$ \\
\hline 9 & 51 & 0,031085838 & $-0,025172816$ & 24 & 66 & 0,036541818 & $-0,016269466$ \\
\hline 10 & 52 & 0,03152043 & $-0,024626459$ & 25 & 67 & 0,036820194 & $-0,015629245$ \\
\hline 11 & 53 & 0,03194542 & $-0,024072601$ & 26 & 68 & 0,037087354 & $-0,014984264$ \\
\hline 12 & 54 & 0,03236068 & $-0,02351141$ & 27 & 69 & 0,037343217 & $-0,014334718$ \\
\hline 13 & 55 & 0,032766082 & $-0,022943057$ & 28 & 70 & 0,037587705 & $-0,013680806$ \\
\hline 14 & 56 & 0,033161503 & $-0,022367716$ & 29 & 71 & 0,037820743 & $-0,013022726$ \\
\hline 15 & 57 & 0,033546823 & $-0,021785561$ & & & & \\
\hline
\end{tabular}

Table 3. Coordinates of Points Located on One Side of the Rotating Piston

\begin{tabular}{|c|c|c|c|c|c|c|c|}
\hline Nr.crt & $\theta_{3}$ & $x_{i}[\mathrm{~m}]$ & $\mathrm{y}_{\mathrm{i}}[\mathrm{m}]$ & Nr.crt & $\theta_{3}$ & $x_{i}[\mathrm{~m}]$ & $\mathrm{y}_{\mathrm{i}}[\mathrm{m}]$ \\
\hline 1 & 70 & 0,038 & $-0,012996788$ & 12 & 81 & 0,06 & $-0,005848555$ \\
\hline 2 & 71 & 0,04 & $-0,012346948$ & 13 & 82 & 0,062 & $-0,005198715$ \\
\hline 3 & 72 & 0,042 & $-0,011697109$ & 14 & 83 & 0,064 & $-0,004548876$ \\
\hline 4 & 73 & 0,044 & $-0,01104727$ & 15 & 84 & 0,066 & $-0,003899036$ \\
\hline 5 & 74 & 0,046 & $-0,01039743$ & 16 & 85 & 0,068 & $-0,003249197$ \\
\hline 6 & 75 & 0,048 & $-0,009747591$ & 17 & 86 & 0,07 & $-0,002599358$ \\
\hline 7 & 76 & 0,05 & $-0,009097751$ & 18 & 87 & 0,072 & $-0,001949518$ \\
\hline 8 & 77 & 0,052 & $-0,008447912$ & 19 & 88 & 0,074 & $-0,001299679$ \\
\hline 9 & 78 & 0,054 & $-0,007798073$ & 20 & 89 & 0,076 & $-0,000649839$ \\
\hline 10 & 79 & 0,056 & $-0,007148233$ & 21 & 90 & 0,078 & 0 \\
\hline 11 & 80 & 0,058 & $-0,006498394$ & & & & \\
\hline
\end{tabular}

Figure 6 shows a quarter of the contour of the rotor. 


\section{AUAST}

Asian Journal of Applied Science and Technology (AJAST)

(Quarterly International Journal) Volume 4, Issue 2, Pages 97-107, April-June 2020

The contour of the rotor profile is symmetrical to the axes of ox and oy, so it is sufficient to draw the contour for a quarter of a quadrant (A, B, C, D) and then by symmetry with respect to oy one can obtain $1 / 2$ of the rotor and then through symmetry with the ox the whole counter of the rotor is obtained (figure 6).

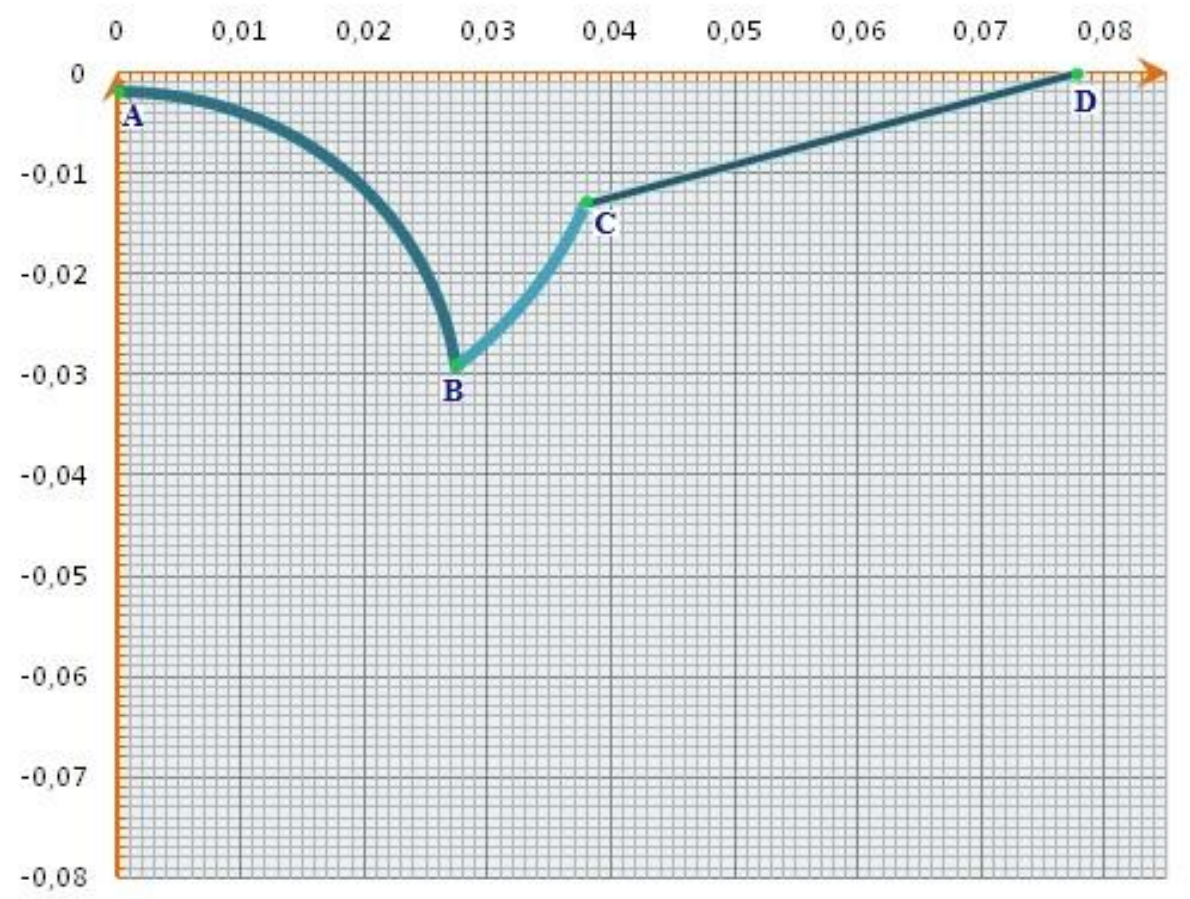

Fig 6: Contour of the Profile of the First Quarter of the Rotor

Based on the data from tables no.2 and no.3, the rotor from figure 7 was built.

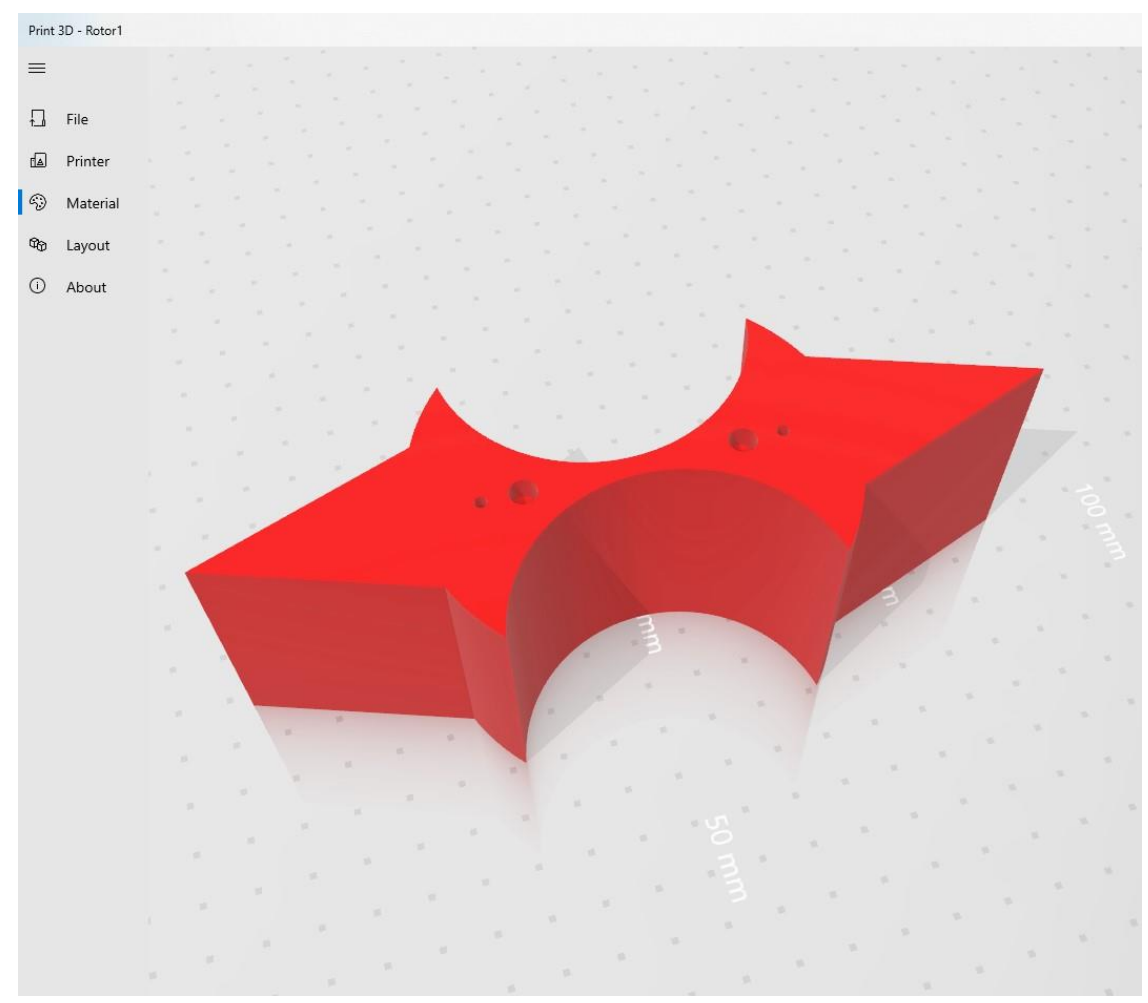

Fig 7: The Contour of the Rotor Profile Provided with Triangular Pistons 
Figure 8 shows a section through the case comprising the two rotors.

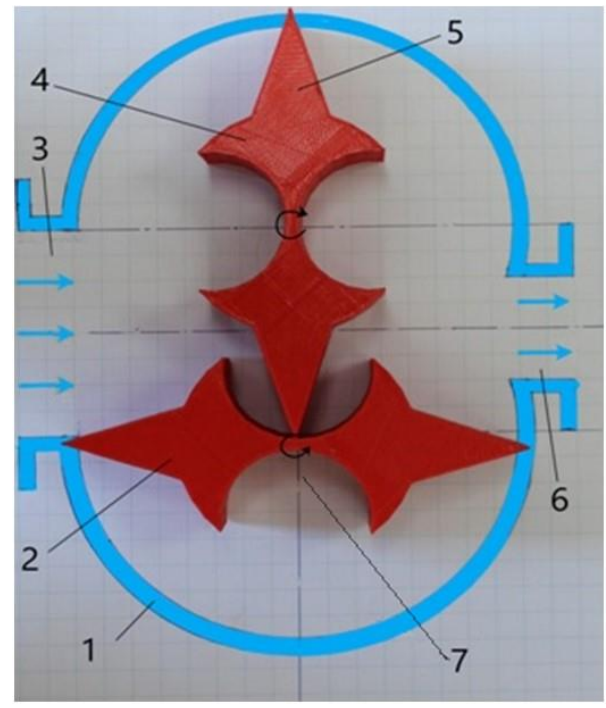

Fig 8: Cross Section through the Rotating Machine with Two Profiled Rotors

1- machine case; 2- lower rotor; 3- suction connection of the fluid; 4- upper rotor; 5- rotating piston;

6- fluid discharge connection; 7- cavity in which the piston of the upper rotor enters.

Figure 9 shows an axonometric view of the housing with the two profiled rotors. Having this mathematical calculation model that specifies the shape of the rotor contour, we proceeded to the development of a rotor execution technology and later to its practical realization.

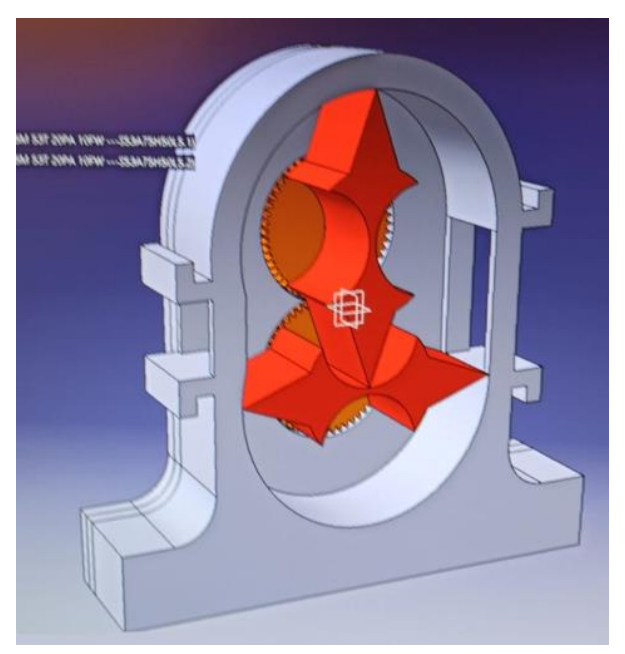

Fig 9: Housing Overview with the Two Rotors

\section{Analysis of the Formula for Calculating the Flow Rate of the Rotating Machine and the Driving Power of} the Machine

In previous papers [11], the expression of calculation of the volumetric flow rate carried by this machine was established:

$$
\stackrel{\mathrm{g}}{V_{u}}=\pi \cdot l \cdot z\left(2 \cdot R_{r}+z\right) \cdot \frac{n_{r}}{30}\left[\mathrm{~m}^{3} / s\right]
$$


In relation 8 it was noted:

- 1 - the length of the rotor $[m]$;

- $\mathrm{z}$ - height of the rotating piston $[\mathrm{m}]$;

- $\mathbf{R}_{\mathrm{r}}-$ the rotor radius $[m]$;

- $\mathrm{n}_{\mathrm{r}}-$ machine speed $[\mathrm{rot} / \mathrm{min}]$.

From figure 9 one can observe that to prevent "reverse flow" a central portion of the $4 \mathrm{~mm}$ thick rotor was left.

The area of the section between the base of the prism and the rotor is neglected. The volume of this prism will be:

$$
V_{p}=A_{\text {bazei }} \cdot l=\frac{1}{2} \cdot b \cdot z \cdot l\left[m^{3} / r o t\right]
$$

The theoretical flow of the machine will be reduced by $V_{p}$,

$$
\stackrel{\mathrm{g}}{V}_{u}=\left[\pi l z\left(z+2 R_{r}\right)-V_{p}\right] \cdot \frac{n_{r}}{30}\left[m^{3} / s\right]
$$

The driving power of the machine will be [12][13]

$$
P=\dot{V} \cdot \Delta p[W]
$$

where:

* I\& volumetric flow rate driven by the machine $\left[\mathrm{m}^{3} / \mathrm{s}\right]$;

* $\Delta \mathrm{p}$ - increasing pressure between suction and discharge $\left[\mathrm{N} / \mathrm{m}^{2}\right]$.

The value of $\Delta \mathrm{p}$ can also be expressed according to the geodetic pumping height $\left(H_{g}\right)$ of the water [14].

$$
\Delta p=p_{H_{2} O} \cdot g \cdot H_{g} \quad\left[N / m^{2}\right]
$$

as a result:

$$
P=\dot{V} \cdot p_{H_{2} O} \cdot g \cdot H_{g} \quad[W]
$$

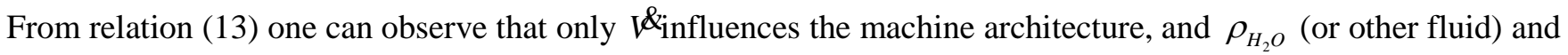
$H_{g}$ influence the theoretical power required by the rotating machine.

\section{Conclusion}

a) For a certain required volumetric flow rate, a certain length of the rotor is chosen according to the execution technology; then the rotor radius is chosen and the height of the rotating piston results.

b) The change of the volumetric flow rate of the rotating machine is made by changing the speed of the engine driving the machine.

The advantages of this machine are: 
- When the machine is operating as a force machine, the motor torque created by the heating medium at the machine shaft is constant during a complete rotation. When the machine is operating as a working machine, the strong moment will also be constant during a complete rotation.

- The motor torque created at the machine shaft is maximum because: $\mathrm{M}=\mathrm{Fb} \sin \alpha$ and the angle $\alpha$ between the force (F) and the force arm (b) is always equal to 90 degrees; conversely, for the working machine the motor torque from the outside to the machine shaft is transmitted to the conveyed fluid with minimal losses.

This rotating machine can carry multiphase fluids, viscous fluids; as a result, it can be used in agriculture, in the fields of energy, petrochemical.

\section{References}

[1] Băran N., "Rotating thermic machines. Working machines. Force machines" (in Romanian), MATRIXROM Publishing House, Bucharest, 2001.

[2] Băran N., "Working rotating thermic machines. Machines with profiled rotors. Blade machines" (in Romanian), MATRIXROM Publishing House, Bucharest, 2003.

[3] Băran N., Răducanu P., A.O. - "Bases of Technical Thermodynamics, Technical Thermodynamics" (in Romanian), POLITEHNICA PRESS Publishing House, Bucharest, 2010.

[4] Exarhu, M., "Pneumatic and hydraulic machines and installations", (in Romanian), Sc. ANDOR SRL., Bucharest, 2011.

[5] Compressor handbook Paul C. Hanlon Editor Library of Congress Cataloging-in-Publication Data TJ990.C623 2001 621.51-dc21.

[6] N. Băran, D. Duminică, D. Besnea, A. Detzortzis, "Theoretical and Experimental Researches Regarding the Performances of a New Type of Rotating Machine with Profiled Rotors", Advanced Materials Research, vol. 488-489, 2012, pp.1757-1761, Mar/2012, Switzerland.

[7] N. Băran, D. Despina, D. Besnea, A. Detzotzis, "Theoretical and experimental researches regarding the performances of a new type of rotating machine with profiled rotors", in $3^{\text {rd }}$ International Conference on Mechanical and Electrical Technology ICMET, Dalin, China.

[8] A. Motorga, "Influence of constructive and functional parameters on the performances of rotating machines with profiled rotors", PhD Thesis, Faculty of Mechanical Engineering and Mechatronics, POLITEHNICA University of Bucharest, 2011.

[9] C-tin. Radu, “Algebră liniară, Geometri Analitică şi Diferenţială”, Editura ALL Bucureşti 1998.

[10] W.Kecs, “Complemente de matematici cu aplicaţii în tehnică”, Editura Tehnică, București 1982.

[11] M. Hawas, N. Băran, "The influence of Fluid Viscosity on the Driving Power of a Rotating Working Machine" International Journal of Innovative Research in Advanced Engineering, vol.1, Issue 4, 2014, pp. 126-131.

[12] E. Isbăşoiu, "Treatise on fluid mechanics”, (in Romania), AGIR Publishing House Bucharest, 2011.

[13] G. Bar Meir, "Basics of fluid mechanics”, North Washtenaw Ave Chicago, IL, 2013.

[14] S. Nazarenko, "Fluid Dynamics via Examples and Solution", CRC Press (Taylor \& Francis Group), 2014. 